\title{
Switzerland on the Internet: An overview of diffusion, usage, concerns and democratic implications
}

\author{
Just, Natascha ; Latzer, Michael ; Metreveli, Sulkhan ; Saurwein, Florian
}

DOI: https://doi.org/10.1016/j.scoms.2013.11.002

Posted at the Zurich Open Repository and Archive, University of Zurich ZORA URL: https://doi.org/10.5167/uzh-93313

Journal Article

Accepted Version

Originally published at:

Just, Natascha; Latzer, Michael; Metreveli, Sulkhan; Saurwein, Florian (2013). Switzerland on the Internet: An overview of diffusion, usage, concerns and democratic implications. Studies in Communication Sciences:148-155. DOI: https://doi.org/10.1016/j.scoms.2013.11.002 
Natascha Just, Michael Latzer, Sulkhan Metreveli and Florian Saurwein: Switzerland on the Internet: An overview of diffusion, usage, concerns and democratic implications; In Studies in Communication Sciences, 2013 forthcoming

Natascha Just, Michael Latzer, Sulkhan Metreveli and Florian Saurwein

Forthcoming in Studies in Communication Sciences, 2013

University of Zurich, IPMZ, Media Change \& Innovation Division Andreasstrasse 15, CH-8050 Zurich, Switzerland

n.just@ipmz.uzh.ch,m.latzer@ipmz.uzh.ch,s.metreveli@ipmz.uzh.ch, f.saurwein@ipmz.uzh.ch

\title{
Switzerland on the Internet:
}

An overview of diffusion, usage, concerns and democratic implications

\begin{abstract}
This article gives multifaceted insights into the current status of Internet use in Switzerland and the related democratic implications. It shows the state of Internet diffusion, digital gaps and the usage patterns of Internet applications. It analyzes people's trust in Internet content and the concerns related to using the Internet. Finally, it explores the extent of political participation online and citizens' views on digital democratization. The results derive from the World Internet Project - Switzerland (WIP-CH), a representative national academic survey embedded in the wider framework of the World Internet Project (WIP).
\end{abstract}

\section{Key Words}

Internet, Switzerland, survey, Internet usage 


\section{Switzerland on the Internet: An overview of diffusion, usage, concerns and democratic implications}

The diffusion of technological innovations such as the Internet is generally accompanied by visions and expectations of social progress and democratization. Conceptions such as electronic democracy, digital democracy and network democracy refer to this potential of the Internet and attendant applications for democracy, e.g., by promising to increase the transparency of the political process, enhance the direct involvement and citizens' participation or improve the quality of opinion formation by opening new channels for information and deliberation (Trechsel, Kies, Mendez, \& Schmitter, 2003; Saurwein, Just, Latzer, \& Metreveli, 2013). In this context it is often argued that democracy could be promoted and strengthened by a broad diffusion of new information and communication technologies (ICTs) and by a proficient and skilled handling of its applications. This alone would provide new opportunities for political engagement and public debate, in essence it would create an easily accessible virtual common public sphere (Giannakoulopoulos, Oikonomou, Oikonomidou, \& Meimaris, 2012; Neumayer \& Raffl, 2008). Because of its long-standing concern with questions of the public sphere and with how the media fulfill important functions for society (e.g., political or democratic functions) communication science has increasingly moved its research interest to the Internet in order to uncover its feasibility for political participation and for assessing related democratic implications (Weare, 2002; Hacker \& van Dijk, 2000). Many empirical examples underline the enabling potential of the Internet to enhance the quality of democracy, e.g., the role of social media for citizen empowerment in the "Arab Spring" (Tufekci \& Wilson, 2012; Khondker, 2011). Dutton (2007, p. 12) argues that the Internet crucially enables individuals to network in new ways that reconfigure and enhance their communicative power - as a type of "Fifth Estate". Chadwick (2008) highlights the low threshold for co-production behavior characteristic of Web 2.0, which provides real new value in online consultation and public policymaking. Despite such promising conditions, visions and examples, several scholars point out that actual progress in exploiting the existing potential for democratization has so far not matched the high expectations. As van Dijk (2009) puts it:

Currently, scarcely any influence of e-Participation projects or experiments on institutional policy and politics can be observed. Few decisions of governments, political representatives and civil servants have changed on account of the input of 
Natascha Just, Michael Latzer, Sulkhan Metreveli and Florian Saurwein: Switzerland on the Internet: An overview of diffusion, usage, concerns and democratic implications; In Studies in Communication Sciences, 2013 forthcoming

citizens in e-Participation. Decision makers doubt the representativeness, surplus value and quality of the input of the new channels. (p. 36)

Optimistic views on the positive impact of the Internet somehow unreflectively consider democratization and political participation to be a direct result of the availability of technology as, for instance, widely proclaimed during the recent Facebook and Twitter "revolutions" of the "Arab Spring". Technology, however, is only an enabler, an opportunity structure (Dolata \& Werle, 2007, p. 20) that allows for new socially created possibilities of action. In practice this means that several factors influence the realization of democratic expectations and visions, and that an overall nation-by-nation assessment of these factors is crucial for a better understanding of the real impact of the Internet on democracy. These factors include the specifics of diffusion and usage of the Internet by way of access disparities and usage differences, which indicate the extent of the first- and second-level digital divide as well as the attitudes that people show towards the Internet and its use, such as their level of trust in Internet content or their views and expectations on its potential for democratization.

Among the barriers likely to inhibit the democratic potential of the Internet is the so-called digital divide, which creates inequalities by differentiated access to the Internet and differentiated use of online applications and content (Papacharissi, 2002). If citizens do not have Internet access and cannot contribute to public-opinion formation, the democratic criterion of equal opportunities for public expression is not fulfilled (Habermas, 1994). Since even in advanced economies not everyone has an Internet connection, sections of society are excluded from the virtual public sphere. Moreover, even citizens who have an Internet connection still remain unequal in their Internet usage skills, the technical quality of access, the applications they use and content they access. These inequalities on the usage level are referred to as the problem of a second-level digital divide (DiMaggio, Hargittai, Celeste, \& Shafer, 2004; Hargittai, 2002). It is argued that sophisticated Internet use serves the expression and enforcement of the interests of qualified users while lower qualification hampers active engagement as well as expression of interests and influence.

In order to understand whether the Internet meets the high expectations attributed to it, an indepth assessment of Internet access and usage data is necessary. Additionally, it is essential to explore peoples' opinions, expectations and concerns regarding the impact of the Internet on democracy. Only by putting all of these relevant aspects in a common perspective research can we assess the contribution of the Internet for democracy and develop a deeper understanding of the reasons for online political engagement or exclusion. Problems of exclusion and the digital divide are discussed in many countries worldwide, but Switzerland 
Natascha Just, Michael Latzer, Sulkhan Metreveli and Florian Saurwein: Switzerland on the Internet: An overview of diffusion, usage, concerns and democratic implications; In Studies in Communication Sciences, 2013 forthcoming

seems of special interest for research on questions regarding the impact of the Internet on democracy. The unique political system in Switzerland, with strong elements of direct democracy, builds on more frequent active involvement of the citizens in the decision-making process than is the case in countries with much stronger reliance representative models of democracy (e.g., Morris, 2000). Can technologies such as the Internet further promote people's participation and empowerment? What are the deficits displayed in divides on the levels of access and usage? How do Swiss citizens use the Internet for political participation? How do people assess the impact of the Internet on citizens' engagement and empowerment in politics?

In order to answer these questions this article investigates issues at the intersection of Internet diffusion and use as well as politics and democracy. It starts by giving comprehensive insights into the current status of Internet use in Switzerland. It shows that the state of Internet diffusion is high but that some significant socio-demographic digital gaps remain. It identifies the usage patterns of various Internet applications for digital information and recreation, ecommerce, digital socializing and content production on the Internet that indicate where second-level digital divide issues are likely to emerge. The article then continues to explore the people's trust in Internet content, the risks of being online and the concerns of the Swiss population related to using the Internet that have an impact on the general attitude of how people behave online. Finally, the last section of the article shows the extent of online political participation, attitudes towards freedom of speech online, and the citizens' view on digital democratization.

The results derive from the World Internet Project - Switzerland (WIP-CH), a representative national academic survey conducted for the first time in 2011 (Latzer, Just, Metreveli, \& Saurwein, 2012a, b, c, d). The survey is based on 1,104 computer-assisted telephone interviews (CATI). The data is representative of the whole Swiss population by gender, age (14 years and above) and the three language regions. The sample has a confidence level of $95 \%$, with a confidence interval of $+/-2.95 \%$. The interviews were conducted between May and June of 2011. The advantage of the CATI method vis-à-vis exclusive online surveys is that it allows for a better representation of the population and also captures non- and ex-users. The WIP-CH is embedded in the wider framework of the Word Internet Project (WIP), one of the leading international, collaborative academic Internet research projects. Since 1999 the WIP has investigated Internet use and its implications for societies and economies in more than 30 countries worldwide, based on a standardized questionnaire that is expandable on a country-by-country basis. For the 2011 Swiss survey, questions regarding Internet and 
Natascha Just, Michael Latzer, Sulkhan Metreveli and Florian Saurwein: Switzerland on the Internet: An overview of diffusion, usage, concerns and democratic implications; In Studies in Communication Sciences, 2013 forthcoming

politics, political participation and trust, among other things, were added, which in part are also asked in other WIP member countries. Accordingly, this paper also takes advantage of the data provided in this global collaborative research network. In order to put Swiss results into an international context, recent data from other WIP partner countries serve as points of reference for cross-national comparisons. International data derive from the World Internet Project International Reports (Cole et al., 2010; 2012) and from the recent WIP country reports conducted in Sweden (Findahl, 2011), New Zealand (Smith, Gibson, Crothers, Billot, \& Bell, 2011), the United Kingdom (Dutton \& Blank, 2011; Dutton, Helsper, \& Gerber, 2009), Poland (Toczyski, Kustra, Rzeźnik, \& Gerszewska 2011) and the USA (Cole et al., 2011).

\section{High Internet diffusion but no end to digital gaps}

During the last two decades the Internet has seen a massive growth. The number of people using it has risen constantly and the impacts of Internet diffusion are evident in many sectors. Statistics on Internet diffusion in societies and economies, data on the availability of broadband connections, and numbers on the use of key Internet applications have become important indicators for understanding the preconditions for countries to exploit the social, economic and political opportunities that the Internet offers. In many Internet statistics, such as the ICT Development Index (ITU), the Networked Readiness Index (WEF) and the Digital Economy Rankings (EIU), north European countries, especially Sweden, Norway, Denmark and Iceland, often score best, along with the Netherlands and some well-developed Asian countries. Today, in some of these countries around nine out of ten people already have access to the Internet.

Digital democratization is a process that depends on support by the political system, citizens and technology. On the part of citizens it depends, among other things, on access to the Internet and readiness for active political participation. A look at these factors in Switzerland reveals that the basic conditions for digital democratization are good, due to high Internet penetration. There are, however, some noteworthy obstacles to full development.

In Switzerland, more than three-quarters $(77 \%)$ of the population $(14+)$ were using the Internet in 2011. With this Internet penetration rate Switzerland belongs to the upper third of countries when compared internationally, but it is not at the forefront. According to comparative data provided by the World Internet Project, Internet penetration is higher in Sweden (88\%), New Zealand (86\%) and in the USA (82\%), for example. Britain (73\%) and Poland (62\%) rank behind Switzerland. On average, Swiss Internet users have been online for 10.5 years and the greatest diffusion took place around the turn of the millennium. 
Natascha Just, Michael Latzer, Sulkhan Metreveli and Florian Saurwein: Switzerland on the Internet: An overview of diffusion, usage, concerns and democratic implications; In Studies in Communication Sciences, 2013 forthcoming

The penetration of private Internet connections in Switzerland is high. 97\% of the Internet users access the Internet at home. $43 \%$ use the Internet at work, which corresponds to a third of the population (33\%) and more than half (55\%) of Swiss employees. $8 \%$ use the Internet at school or at the university. Further, there is a high penetration of high-capacity Internet connections. Three-quarters of those who use the Internet at home have a broadband connection. $26 \%$ of the Internet users access the Internet mobile en route. Within a short period of time, the smartphone has become the number one access-device for mobile Internet, with $54 \%$ of mobile Internet users accessing the Internet via smartphone, compared to $25 \%$ using laptops.

The average time a person spends on the Internet in Switzerland is 1 hour 45 minutes per day, according to the respondents' own estimates. This corresponds to 12.3 hours per week and means that the Swiss spend less time on the Internet than people in Poland (13.5 hours/week), in the USA (18.3 hours) and Sweden (20 hours). Only 18\% of Internet users in Switzerland are "heavy users" who are online more than 24 hours a week (in the USA: $29 \%$ ). $40 \%$ of the Swiss Internet users are "light users", with an Internet use of up to 5 hours per week. The proportion of light users in Switzerland is twice as high as in the USA (21\%).

The time spent on the Internet depends on access spots. On average, the Swiss population uses the Internet 5.6 hours per week at home, 3.3 hours per week at work and 0.4 hours per week mobile en route. Remarkably, almost a third of Internet users (31\%) use the Internet for professional purposes at home and more than a fifth of the time spent on the home computer (1.2 hours per week) is dedicated to professional purposes. Swiss students use the Internet 4.2 hours per week at school or university and therefore far less than students in Sweden (7 hours). The group of mobile Internet users spends an average of 19 minutes per day with mobile Internet, which indicates that they use it mobile en route only occasionally.

Although Switzerland is in the upper segment in various comparative international ICT and Internet statistics, indicators of a digital divide are also apparent. $23 \%$ of the population do not use the Internet. The "age gap" is very pronounced between the age group 60 and above on the one hand and younger generations on the other. People who do not use the Internet are also represented above average in the population groups with a lower education (49\%), lower income $(50 \%)$ or without employment $(40 \%)$. The penetration of mobile Internet is borne primarily by particular population strata (see Figure 1).

Figure 1: Socio-demographic patterns of the use of mobile Internet $\boldsymbol{H E R E}$ 
Natascha Just, Michael Latzer, Sulkhan Metreveli and Florian Saurwein: Switzerland on the Internet: An overview of diffusion, usage, concerns and democratic implications; In Studies in Communication Sciences, 2013 forthcoming

In the upper income groups and among the more highly educated population, the use of mobile Internet has already reached 30-40\%. In low-income and low-educated groups, just about one in ten use the mobile Internet.

There is hardly any gender gap in Switzerland any more as regards Internet use in general. According to the survey, $75 \%$ of women and $79 \%$ of men are now online. However, women use the Internet less intensively than men do, and the gender difference is also more clearly evident with regard to the take-up of mobile Internet. While a quarter of men have already adopted mobile Internet, the diffusion rate among women is only $15 \%$.

In general, a sharp reduction of the digital divide is not in sight. In recent years, the rate of growth has continuously decreased. Reasons for remaining unconnected vary. For one in ten non-users the barriers are the absence of technical equipment (11\%), lack of technical knowhow $(10 \%)$ or financial affordability $(10 \%)$. However, the predominant reason for not using the Internet is a lack of interest. Almost half (45\%) of the non-users say that they are not interested in the Internet and that they do not see any added value of being online. Only one in five non-users $(20 \%)$ feel they are missing anything without the Internet, and almost two thirds (64\%) are not planning to access it in the foreseeable future. However, age-related differences are very pronounced as regards motivation to access the Internet. The 19-24-yearold non-users feel they are missing something without the Internet (49\%) significantly more often than the older generations (10-20\%). Accordingly, access plans are clearly more common among younger non-users (79\%). Low motivation for access is widespread in older age groups.

Besides factual digital gaps, which are related to the availability of an Internet connection and to practical Internet usage, there are also perceived break lines. These are evident in varying attitudes towards the Internet and in the diverging self-assessment regarding one's own abilities in Internet use. Almost three-quarters of Swiss Internet users (72\%) regard their own Internet abilities as good, very good or excellent. $27 \%$ admit to handling the Internet badly or just adequately, women (34\%) slightly more than men (21\%). 42\% of the Swiss population feel not at all or only marginally integrated into the information society. Unsurprisingly, the proportion of people who feel uninvolved is particularly high among non-users (74\%). But even among Internet users, a third (33\%) do not feel involved or feel only marginally involved in the information society. This phenomenon was also observed in Sweden, where $44 \%$ of the population do not feel they belong to the information society, although Sweden ranks top in many ICT and Internet indicators (Findahl, 2010, p. 51). 
Natascha Just, Michael Latzer, Sulkhan Metreveli and Florian Saurwein: Switzerland on the Internet: An overview of diffusion, usage, concerns and democratic implications; In Studies in Communication Sciences, 2013 forthcoming

\section{Use of Internet applications: A multipurpose infrastructure}

Research on the digital divide in advanced economies has increasingly shifted away from analyzing access issues only towards assessing additionally how people use Internet applications. This is where problems of the second-level digital divide, which may have important effects on how people engage politically via the Internet, manifest themselves. The Internet has established itself as a multipurpose infrastructure. People use a broad range of Internet applications for orientation and information, recreation and entertainment, for ecommerce, for building and maintaining social relations, and for the creation and distribution of their own content.

In Switzerland, applications such as e-mail (97\%) and search engines (93\%), which can be used for various purposes, are the most popular among Internet users. Altogether, using the Internet for information purposes is more widespread than its use for entertainment purposes. $79 \%$ of Internet users are looking for product information, three-quarters for local, national or international news and for travel information. Around 70\% are looking for online information from public authorities (71\%) and for health-related information (69\%). For digital recreation, two thirds watch videos on video portals (65\%), around half of all Internet users download music from the Internet or listen to music online (54\%), slightly fewer use web radio services (44\%). More than a third use the Internet at least occasionally to watch television programs live $(35 \%)$ or on demand $(37 \%)$, and $33 \%$ play online games. $E$ commerce offerings and transaction services are also well established in Switzerland. 67\% of users compare prices of products and services, $65 \%$ buy things online and $64 \%$ use online banking. Interaction and digital socializing is carried out especially via e-mail (97\%) and increasingly via online social networks (54\%). In addition, $42 \%$ use instant messaging for communication, $30 \%$ use Internet telephony, one fifth visit chat rooms, and $9 \%$ say that they use contact and dating services.

In the last few years the technical barriers for content production and distribution have decreased owing to the diffusion of user-friendly applications for user-generated content (UGC). Nevertheless, in terms of outreach, active content production still clearly lags behind passive consumption. Uploading pictures (59\%) is by far the most widespread activity and this is not only a Swiss phenomenon. Photo uploading scores best among UGC activities in other WIP countries too (e.g., UK: 53\%, Sweden: 49\%). Other applications for content production are used by a maximum of one third of all Internet users. 33\% of all Internet users make postings or comments on discussions boards, $29 \%$ upload music videos, $28 \%$ make comments on news boards or weblogs (in Sweden: 47\%), 18\% work on a personal blog and 
Natascha Just, Michael Latzer, Sulkhan Metreveli and Florian Saurwein: Switzerland on the Internet: An overview of diffusion, usage, concerns and democratic implications; In Studies in Communication Sciences, 2013 forthcoming

$13 \%$ upload their own videos. Even though the proportion of content producers in Switzerland lags behind that of content consumers, it has to be emphasized that more than a million Swiss now share their home-made digital content and therefore contribute to the growth of the socalled Web 2.0.

Among the many Internet applications, social networking sites have attracted a great deal public attention during last couple of years. In Switzerland, 47\% of Internet users say they log into private social networks and $22 \%$ use professional social networks (see Figure 2).

\section{Figure 2: Use of online social networks HERE}

In total, half of the Internet users (54\%) use online social networks. People over 60 use online social networks significantly less (23\%) than those in the $14-29$ age group (88\%). Further, the diffusion of social online networks in Switzerland is not as great as in other WIP countries such as in the UK (60\%), Sweden (62\%), New Zealand (64\%), Poland (71\%), and in the USA $(81 \%)$. The number of daily users of social online networks in Switzerland (18\%) is also lower than in Poland (24\%), New Zealand (28\%), Sweden (35\%) and in the USA (44\%). 26\% of the Swiss Internet users actively publish "status updates". $6 \%$ say they update their status daily and $8 \%$ make updates on a weekly basis. This means that the group of intensive and very active users of social online networks in Switzerland is rather small and amounts to $14 \%$ of all Internet users.

Data on daily and mobile Internet use make it possible to show which applications are becoming part of the daily routines of Internet users. Using e-mail (80\%) and search engines (55\%), browsing the web (35\%) and reading news (27\%) rank high when it comes to the question of daily usage. In general, interaction applications such as social online networks and instant messaging rank higher in terms of daily and mobile use as compared to their general use. In contrast, daily and mobile use for e-commerce and transaction services is comparatively low. Data on the frequency of use of particular applications also points to interesting patterns and implications. For example, although more than one third of Internet users watch television programs live or on demand online (35-37\%), the percentage of daily Internet televisions users is very low $(2-3 \%)$. A strong trend from traditional television toward Internet television is therefore not observable. News services are especially heavily used on the Internet. $75 \%$ of all Internet users say that they look for local, national and international news, and $27 \%$ look for news on a daily basis. Nevertheless, reading print versions of newspapers is still widespread among Internet users in Switzerland. 83\% of Internet users read daily newspapers regularly, and so far only $7 \%$ of Internet users have cancelled their 
Natascha Just, Michael Latzer, Sulkhan Metreveli and Florian Saurwein: Switzerland on the Internet: An overview of diffusion, usage, concerns and democratic implications; In Studies in Communication Sciences, 2013 forthcoming

newspaper subscription because they can also read the news online. In the USA, the percentage of cancelations is significantly higher at $25 \%$.

The survey also shows results on usage patterns and digital gaps on the application level. The Internet is not equally used across generations. Above all, the applications for interaction are significantly more common among younger users than among older ones. The use of the Internet for digital recreation and for the production and distribution of user-generated content is also more widespread among younger users. In contrast, e-commerce services are used to a larger extent by older users. Altogether, the data show several age-related differences at the application level. On average, younger people use a broader variety of Internet applications than older ones, and young users more typically interact and recreate digitally, while older people manage their commerce-related tasks online.

In addition, differences appear in the use of applications for recreation, information and commerce among education groups. Entertainment services are more widespread among the less well educated, and information applications among better educated people. Moreover, better educated people use commerce-related applications such as e-banking and e-shopping to a higher extent than the less well educated. This partly confirms the "usage gap" observed by van Dijk $(2005,2008)$ according to which the higher educated primarily use the advanced and "serious" applications of the Internet that serve their occupational and educational careers, while the lower educated make relatively greater use of simple applications for entertainment, basic communication, shopping and auctions.

\section{Worried online: Trust in content and concerns}

The Internet offers of a broad range of new opportunities for information, self-expression, and political participation. It is often argued that the extent to which people use the Internet for political participation is connected to the degree of trust in online content and the general worries they associate with Internet use (Mou, Atkin, \& Fu, 2011; Mou, Atkin, Fu, Lin, \& Lau, 2013). Content on the Internet is, for example, often criticized for low level of trustworthiness due to the anonymity of contributors, lack of editorial control and low professional standards. How do Swiss Internet users appraise the credibility of content on the Internet, and what sources of information do they trust?

Overall, people in Switzerland regard slightly more than half of the content on the Internet as trustworthy. 39\% say that half of the content online is trustworthy, 35\% think most of it is trustworthy and $1 \%$ believe that all of the content on the Internet is trustworthy. Internet users assess the trustworthiness of Internet content as slightly higher than non-users, but Internet 
Natascha Just, Michael Latzer, Sulkhan Metreveli and Florian Saurwein: Switzerland on the Internet: An overview of diffusion, usage, concerns and democratic implications; In Studies in Communication Sciences, 2013 forthcoming

users' evaluations of credibility vary considerably depending on the different sources of information. Internet offers from professional information suppliers such as the public service broadcasters and public authorities are generally considered to be very credible. Significantly less trust is put in user-generated content in online social networks and blogs, where only half or even less of the available content is considered credible. However, trust in user-generated content differs with the age of users. Among young Internet users (14-29 years), a majority consider more than half of the content in blogs $(59 \%)$ and on social networking sites $(64 \%)$ to be credible. Among users over 60 these proportions are considerably lower, 37\% for social networking sites and $18 \%$ for blogs.

Credibility may be one of the relevant influencing factors when it comes to the assessment of the relevance of information sources for individual users. According to the survey results the most relevant sources of information in Switzerland are interpersonal contacts. In terms of the entire Swiss population, the Internet polls badly as source of information when compared to traditional media. It clearly ranks behind newspapers, radio and television, because the Internet does not play a major role for the many non-users, who make up almost a quarter of the population. For Internet users, however, the Internet is shoulder to shoulder with newspapers as a source of information, followed by radio and television (see Figure 3).

\section{Figure 3: Relevance of sources for information and entertainment for Internet users $\boldsymbol{H E R E}$}

The high relevance of the newspaper is specific to Switzerland. In many other WIP countries the Internet clearly ranks top as a source of information (Cole et al., 2010, p. 212; Cole et al., 2012, p. 145). In a few WIP partner countries television is considered to be the most important source of information (Sweden, Poland, Cyprus/Greek-Cypriots). Additionally, the Swiss results show that the Internet is more important for information than for entertainment. Even for Internet users, the Internet lags behind television and radio as a source of entertainment. However, inter-personal contacts are again by far the most relevant of the various sources for entertainment.

Using the Internet is also associated with a range of risks for individual Internet users and with risks for social relations in societies. In Switzerland $72 \%$ of the respondents, for example, believe that using the Internet can be addictive. It is often said, that people spend much time on the Internet and it is sometimes assumed that Internet use may negatively affect real-life social contacts (e.g., Turkle, 2011). This cannot be confirmed across the board for Switzerland. Swiss Internet users devote five hours more to face-to-face contacts with their families (3.4 hours), friends (1.3 hours) and in associations ( 0.3 hours) than non-users during 
Natascha Just, Michael Latzer, Sulkhan Metreveli and Florian Saurwein: Switzerland on the Internet: An overview of diffusion, usage, concerns and democratic implications; In Studies in Communication Sciences, 2013 forthcoming

an average week. Two thirds of Internet users say that using the Internet has not affected the intensity of their personal contacts. As far as people observe any changes in social contacts because of using the Internet, they say that social contacts have rather increased than decreased. $28 \%$ of users say that contact with friends increased, $27 \%$ have more intensive contacts with people in their professional environment, and $22 \%$ have more contact with people who share their hobbies.

$70 \%$ of respondents say that the Internet has not affected the contacts with their families. For $16 \%$ family contacts increased because of the Internet, while $12 \%$ say that family contacts decreased. In the USA, opposite trends are observable. Over the last decade the proportion of people who say their family contacts have diminished significantly has increased - from $8 \%$ in 2000 to 34\% in 2010 (USC Annenberg School Center for the Digital Future, 2012, p. 19). Another approach to investigate social implications of Internet use is to ask whether people feel neglected when members of their family or friends are online. In general, $23 \%$ to $31 \%$ say that they sometimes feel neglected due to the media use in their household. $3 \%$ to $4 \%$ have this feeling often. Across different media, television is mentioned most frequently as the reason for feeling neglected (31\%), followed by the Internet $(27 \%)$, the telephone $(26 \%)$ and print media (23\%).

Besides the potential social impact, using the Internet is also often associated with risks regarding fraud and violations of privacy. In Switzerland, 39\% of the population are very or even extremely worried when using their bank/credit card information online, $33 \%$ are slightly worried. In total, $72 \%$ are more or less worried when using bank/credit cards online. In Sweden, this number dropped from $72 \%$ in the year 2000 to $24 \%$ in 2010 (Findahl, 2010, p. 24). In Switzerland, 3\% of the Internet users say that their credit card or bank card information has in fact been stolen or misused. To a similar extent (5\%), Internet users had had negative experiences with cyber-bullying. Almost every third Internet user (29\%) has the feeling that their personal data have been misused or passed on. People in Switzerland are noticeably concerned about data protection and online surveillance. Companies ("big business") are thereby met with greater skepticism than the government ("big brother"). Swiss Internet users are considerably more concerned that their online behavior is controlled by companies $(43 \%)$ than by the government (28\%). Similarly, US Americans are more afraid of control by companies (48\%) than of governmental surveillance (38\%) (Cole et al., 2011, p. 86).

In general, worries about the Internet rise with the increasing age of Internet users. For example, while only $24 \%$ of $14-29$-year-olds are worried about surveillance by companies, for 
Natascha Just, Michael Latzer, Sulkhan Metreveli and Florian Saurwein: Switzerland on the Internet: An overview of diffusion, usage, concerns and democratic implications; In Studies in Communication Sciences, 2013 forthcoming

people over 60 this rises to 59\%. Similar results are shown for credit-card use online. Concerns are far more widespread in the 60+ age group (49\%) as compared to the younger user group (21\%). However, not only the older generations are more concerned about using the Internet. Internet users who consider their Internet abilities to be poor, for example, worry more than the average Internet user, and the feeling that personal data has been misused is slightly more widespread among Internet users with very good or excellent abilities.

In order to counter the risks related to Internet use, one may resort to individual selfprotection, rely upon self-regulation by the industry and/or advocate strengthening governmental regulations. In Switzerland, $25 \%$ of the population believe the government should increase Internet regulation and 38\% argue against stronger governmental regulation. The rejection of stronger state regulation is more widespread among Internet users in general, and among young Internet users and heavy Internet users in particular. Support for more governmental regulation is higher among non-Internet users, older users and light users. Moreover, the support for governmental regulation also increases with decreasing abilities of Internet users. Sometimes it is argued that the user segment with low abilities desires state protection while the segment with strong competences desires freedom from state intervention (DIVSI, 2012, p. 157). However, our statistical tests do not confirm across the board that the desire for more or less governmental regulation is directly affected by the individual abilities in handling the Internet. Support for stronger state regulation is surprisingly high especially in the user segment with the best abilities. The most competent users may be particularly aware of the limitations of individual self-protection and understand the need for state regulatory backing.

\section{Internet, politics and democracy: Predominantly interested, partly engaged but largely skeptical}

In order to comprehensively assess the Internet's potential for digital democratization and political participation, the access disparities, usage differences and the concerns people have when using the Internet need to be complemented by further factors. This last section is therefore devoted to the state of online participation and citizens' views on electronic democratization in Switzerland. More than half of the Swiss population (59\%) are interested in politics. $21 \%$ say they are very interested in politics and $38 \%$ are somewhat interested. Only $15 \%$ say that they are not interested in politics at all. There is hardly any difference between Internet users and non-users regarding political interest.

The political interest of the Swiss population is also partially reflected in active political participation. $40 \%$ search for information on political issues, $17 \%$ take part in political 
Natascha Just, Michael Latzer, Sulkhan Metreveli and Florian Saurwein: Switzerland on the Internet: An overview of diffusion, usage, concerns and democratic implications; In Studies in Communication Sciences, 2013 forthcoming

discussions, $7 \%$ have been involved in some form of protest and $4 \%$ have produced political media during the last year. Internet users are more active in matters of political participation than non-users. Searching for information and joining political discussions, for example, are more widespread among Internet users than among non-users. However, the Internet does not play the same role for all forms of political participation. It is used considerably more for the search for political information than for participation in political discussions. $83 \%$ of politically active Internet users look up political information online, but only $34 \%$ participate in political discussions on the Internet. Thus, even among those Internet users who do in fact participate in political debates, two thirds (66\%) discuss political issues exclusively offline. Altogether, "offline participation" still plays a very important role for Internet users too. The Internet makes political participation easier, but online participation does not replace offline participation.

One of the reasons why people prefer offline to online debates is that the Internet is not regarded as a safe place for the expression of personal political views in Switzerland. $46 \%$ of all respondents do not think it is safe to talk about politics on the web. Only $22 \%$ consider it safe to voice their views about politics while online. In the USA, for example, $33 \%$ feel safe expressing their political views online (Cole et al., 2011, p. 178).

Online political debates may also comprise criticism of the government and the expression of extreme political ideas. What are the opinions of the Swiss regarding freedom of speech on the Internet? Criticism of the government and the expression of extreme ideas are not unreservedly endorsed in Switzerland. 29\% of the respondents disapprove of free criticism of the government in the Internet. Just about half of the Swiss population (47\%) agree with the notion that people should be free to criticize their government on the Internet. For comparison: in the USA, $66 \%$ of respondents agree or strongly agree that people should be free to criticize the government online and only $15 \%$ of respondents disagree with the idea. In Switzerland, about a third (31\%) think that it is all right when people express their opinions on the Internet, even if these are extreme, while $41 \%$ disagree with this idea. In the USA, in contrast, a majority of $52 \%$ agree with the statement that people should be able to express their ideas on the Internet, even if they are extreme. $22 \%$ percent of respondents disagree with full expression of extreme ideas (Cole et al., 2011, p. 181). The differences between Switzerland and the USA may be explained by differing political traditions. In the USA "freedom of speech" is one of the building blocks of US democracy and society and is deepseated with the First Amendment. In Switzerland social peace and political consensus are of high value and traditionally play a major role in political practice. Thus the room for 
Natascha Just, Michael Latzer, Sulkhan Metreveli and Florian Saurwein: Switzerland on the Internet: An overview of diffusion, usage, concerns and democratic implications; In Studies in Communication Sciences, 2013 forthcoming

acceptance of extreme ideas may be narrower. However, differences regarding the attitudes towards freedom of speech on the Internet are also evident in Switzerland. Internet users are more in favor of free expression of ideas and free criticism of government online than nonusers.

Online participation and freedom of speech on the Internet are supposed promote the democratic process and democratic quality. But what are the results of online engagement and how do people estimate the impact of the Internet on politics and democracy? Most notably there is great skepticism toward the impact of the Internet on democratic quality. Only a minority of the Swiss population believe that the Internet will promote citizens' empowerment (18\%) and political involvement (11\%). Similarly, only a small minority think that the Internet enhances people's understanding of politics (20\%) and the responsiveness of decision-makers (15\%). At 3-6\%, the number of people who are very convinced of positive effects caused by the Internet is very low for all four items (empowerment, involvement, understanding, responsiveness). On the other hand, more than $40 \%$ of the respondents do not believe there are positive effects, and non-users are slightly more skeptical than Internet users. A look at comparative data from the WIP confirms the impression that the Swiss are rather skeptical about the impact of the Internet on political empowerment (Figure 4).

\section{Figure 4: Belief in better political responsiveness because of the Internet HERE}

Across all WIP countries people are asked if they agree with the statement that "by using the Internet public officials will care more about what people like you think." In Switzerland only $15 \%$ of the population agree with this statement. Together with Hungary $(6 \%)$ and Cyprus/Greek-Cypriots (11\%) Switzerland forms the block of the most skeptical nations in this regard. Far less than $20 \%$ of the populations in these three countries believe that public officials will care more about what people think because of Internet. In most of the other nations surveyed, $20 \%$ to $35 \%$ believe in positive effects of the Internet on political responsiveness. The proportion of optimistic people is particularly high in Taiwan (67\%) and Portugal (58\%) (Cole et al., 2012, p. 129).

Altogether the results on Internet and politics show that people in Switzerland are predominantly interested in politics, partly engaged but remain largely skeptical. The results point to significant barriers for online political participation that are rooted in citizens' skepticism regarding the de-facto impact of online engagement and distrust of political online communication. Skepticism and distrust have therefore to be considered as central factors of influence in analyses on the status and progress of electronic democratization. 
Natascha Just, Michael Latzer, Sulkhan Metreveli and Florian Saurwein: Switzerland on the Internet: An overview of diffusion, usage, concerns and democratic implications; In Studies in Communication Sciences, 2013 forthcoming

\section{Conclusions}

This article offers a comprehensive profile of Switzerland on the Internet based on data from a national academic survey conducted in 2011. Following its argument that an appraisal of the widely accepted democratic potential of the Internet requires a comprehensive assessment of an interrelated set of factors, it explores Internet diffusion, the usage patterns of various Internet applications, people's trust in Internet content and the concerns related to using the Internet. It reflects the democratic implications of disparate Internet access and usage in Switzerland (first- and second-level digital divide) and investigates the citizens' belief in digital democratization. Altogether, the results of the analyses may be summarized as follows. Digital democratization is a process that depends, among other things, on access to the Internet and readiness for active political participation. A look at these factors in Switzerland reveals that the basic conditions for digital democratization are good, with some noteworthy obstacles to full development however. At $77 \%$ the Internet penetration is high, but indicators of a digital divide are also apparent. Especially the "age gap" is very pronounced and inhibits older people from online political participation. Opportunities to access the virtual public sphere are not distributed equally across the generations.

Moreover, distinct gaps are also apparent among Internet user groups, related to differences in Internet usage that relate to problems associated with the second-level digital divide. Information applications especially are more widespread among the better educated, while the lower educated make more use of entertainment services. From a democratic point of view such differences pose the danger that lower qualification levels may hamper active political engagement online and lead to an under-representation of interests in public debates and little influence on public-opinion formation.

Finally, the survey results show that people in Switzerland are predominantly interested in politics and partly engaged in online political debates. But citizens remain largely skeptical regarding a positive democratic impact of the Internet. Only a minority of the Swiss population believes that the Internet will further promote citizens' empowerment, political involvement, people's understanding of politics and the responsiveness of decision-makers. The peculiarities of the Swiss political system may provide an explanation for this. Instruments of direct democracy (i.e., referendums) are well developed in Switzerland. The opportunities for participation are already manifold in the analog world. This provides a highlevel benchmark for additional enhancements of involvement by digital means. Trust and belief in the promises of "digital democratization" may therefore be higher in less advanced 
Natascha Just, Michael Latzer, Sulkhan Metreveli and Florian Saurwein: Switzerland on the Internet: An overview of diffusion, usage, concerns and democratic implications; In Studies in Communication Sciences, 2013 forthcoming

democracies. Further international comparative research may contribute to clarifying and explaining differences across countries, which may be accomplished by drawing on the comprehensive international database of the WIP.

\section{References}

Chadwick, A. (2008). Web 2.0: New challenges for the study of e-democracy in an era of informational exuberance. ISJLP, 5(9), 9-42.

Cole, J., Suman, M., Schramm, P., Zhou, L., Salvador, A., Chung, J. E., \& Lebo, H. (2010). World Internet Project international report 2010. Los Angeles: USC Annenberg School Center for the Digital Future.

Cole, J., Suman, M., Schramm, P., Lunn, R., Zhou, L., Salvador, A., . . Lebo, H. (2011). The 2011 digital future report. Surveying the digital future year ten: A portrait of Americans on the Internet. Los Angeles: USC Annenberg School Center for the Digital Future.

Cole, J., Suman, M., Schramm, P., Lunn, R., Zhou, L., Salvador, A., . . \& Lebo, H. (2012). World Internet Project international report. Third Edition. Los Angeles: USC Annenberg School Center for the Digital Future.

DiMaggio, P., Hargittai, E., Celeste, C., \& Shafer, S. (2004). From unequal access to differentiated use: A literature review and agenda for research on digital inequality. In K. M. Neckerman (Ed.), Social Inequality (pp. 355-400). New York: Russell Sage Foundation.

DIVSI - Deutsches Institut für Vertrauen und Sicherheit im Internet (2012). DIVSI MilieuStudie zu Vertrauen und Sicherheit im Internet. Hamburg: Author.

Dolata, U., \& Werle, R. (2007). Bringing technology back in. Technik als Einflussfaktor sozioökonomischen und institutionellen Wandels. In: U. Dolata \& R. Werle (Eds.), Gesellschaft und die Macht der Technik: Sozioökonomischer und institutioneller Wandel durch Technisierung (pp. 15-43). Frankfurt a. M.: Campus.

Dutton, W. H. (2007). Through the network of networks - the fifth estate. Manuscript. Oxford: Oxford Internet Institute.

Dutton, W. H., \& Blank, G. (2011). Next generation users: The Internet in Britain. Oxford Internet Survey 2011. Oxford: Oxford Internet Institute.

Dutton, W. H., Helsper, E. G., \& Gerber, M. M. (2009). The Internet in Britain 2009. Oxford Internet Survey 2009. Oxford: Oxford Internet Institute.

Findahl, O. (2010). Swedes and the Internet 2010. World Internet Project Sweden. Stockholm: The Internet Infrastructure Foundation, .SE.

Findahl, O. (2011). Swedes and the Internet 2011. World Internet Project Sweden. Stockholm: The Internet Infrastructure Foundation, .SE. 
Natascha Just, Michael Latzer, Sulkhan Metreveli and Florian Saurwein: Switzerland on the Internet: An overview of diffusion, usage, concerns and democratic implications; In Studies in Communication Sciences, 2013 forthcoming

Giannakoulopoulos, A., Oikonomou, S., Oikonomidou, R., \& Meimaris, M. (2012). Edeliberation revisited under the scope of web 2.0 evolution. Retrieved from http://www.researchgate.net/publication/232250856_EDeliberation_Revisited_under_the_Scope_of_Web_2.0_Evolution/file/d912f507ea12a12a28. pdf

Habermas, J. (1994). Three normative models of democracy. Constellations, 1(1), 1-10.

Hacker, K., L., \& van Dijk, J. (Eds.). (2000). Digital democracy: Issues of theory and practice. London: Sage.

Hargittai, E. (2002). Second-level digital divide: differences in people's online skills. First Monday, 7(4). Retrieved from http://journals.uic.edu/ojs/index.php/fm/article/view/942/864

Khondker, H., H. (2011). Role of the new media in the Arab Spring. Globalizations, 8(5), 675-679.

Latzer, M., Just, N., Metreveli, S., \& Saurwein, F. (2012a). Internetverbreitung und digitale Bruchlinien in der Schweiz. Themenbericht aus dem World Internet Project - Switzerland 2011. Zürich: Universität Zürich.

http://www.mediachange.ch/media/pdf/publications/Verbreitung_und_Bruchlinien.pdf

Latzer, M., Just, N., Metreveli, S., \& Saurwein, F. (2012b). Internet und Politik in der Schweiz. Themenbericht aus dem World Internet Project - Switzerland 2011. Zürich: Universität Zürich. http://www.mediachange.ch/media/pdf/publications/Internet_und_Politik.pdf

Latzer, M., Just, N., Metreveli, S., \& Saurwein, F. (2012c). Internet-Anwendungen und deren Nutzung in der Schweiz. Themenbericht aus dem World Internet Project - Switzerland 2011. Zürich: Universität Zürich.

http://www.mediachange.ch/media/pdf/publications/Anwendungen_Nutzung.pdf

Latzer, M., Just, N., Metreveli, S., \& Saurwein, F. (2012d). Vertrauen und Sorgen bei der Internet-Nutzung in der Schweiz. Themenbericht aus dem World Internet Project Switzerland 2011. Zürich: Universität Zürich. http://www.mediachange.ch/media/pdf/publications/Vertrauen_Sorgen.pdf

Morris, D. (2000). Direct democracy and the Internet. Loyola of Los Angeles Law Review, 4(1), 1033-1054.

Mou, Y., Atkin D., \& Fu, H. (2011). Predicting political discussion in a censored virtual environment. Political Communication, 28(3), 341-356.

Mou, Y., Atkin, D., Hanlong, F., Lin, C. A., \& Lau, T. Y. (2013). The influence of online forum and SNS use on online political discussion in China: Assessing "Spirals of Trust". Telematics and Informatics, 30(4), 359-369.

Neumayer, C., \& Raffl, C. (2008). Facebook for global protest: The potential and limits of social software for grassroots activism. Proceedings of the 5th Prato Community Informatics 
Natascha Just, Michael Latzer, Sulkhan Metreveli and Florian Saurwein: Switzerland on the Internet: An overview of diffusion, usage, concerns and democratic implications; In Studies in Communication Sciences, 2013 forthcoming

\& Development Informatics Conference. Retrieved from

http://cirn.infotech.monash.edu.au/assets/docs/prato2008papers/raffl.pdf

Papacharissi, Z. (2002). The virtual sphere: The Internet as a public sphere. New Media \& Society, 4(1), 9-27.

Saurwein, F., Just, N., Latzer, M., \& Metreveli, S. (2013). A skeptical citizen's view of digital democratization: Switzerland in the international context. Working Paper of Media Change \& Innovation Division. Zurich: University of Zurich.

Smith, P., Gibson, A., Crothers, C., Billot, J. \& Bell, A. (2011). The Internet in New Zealand 2011. World Internet Project New Zealand. Auckland: Institute of Culture, Discourse \& Communication, AUT University.

Toczyski, P., Kustra, A., Rzeźnik, J., \& Gerszewska, M. (2011). World Internet Project. Poland 2011. Warsaw: Agora S.A. \& TP Group.

Trechsel, A., Kies, R., Mendez, F., \& Schmitter, P. C. (2003). Evaluation of the use of new technologies in order to facilitate democracy in Europe. Research report. Retrieved from http://cies.iscte.pt/en/destaques/pdf/1.pdf

Turkle, S. (2011). Alone together: Why we expect more from technology and less from each other. New York: Basic Books.

Tufekci, Z., \& Wilson, C. (2012). Social Media and the decision to participate in political protest: Observations from Tahrir Square. Journal of Communication 62(2), 363-379.

USC Annenberg School Center for the Digital Future (2012). Special report: America at the digital turning point. Los Angeles: Author.

Van Dijk, J. (2005). The deepening divide, inequality in the information society. Thousand Oaks: Sage.

Van Dijk, J. (2008). The digital divide in Europe. In: A. Chadwick \& P. N. Howard (Eds.), The handbook of Internet politics. London / New York: Routledge.

Van Dijk, J. (2009). Domain report of participation in policy making: EU-SMART social impact of ICT. Research report commissioned by the European Commission.

Weare, C. (2002). The Internet and democracy: The causal links between technology and politics. International Journal of Public Administration, 25(5), 659-691. 
Natascha Just, Michael Latzer, Sulkhan Metreveli and Florian Saurwein: Switzerland on the Internet: An overview of diffusion, usage, concerns and democratic implications; In Studies in Communication Sciences, 2013 forthcoming

\section{Figures}

Figure 1: Socio-demographic patterns of the use of mobile Internet

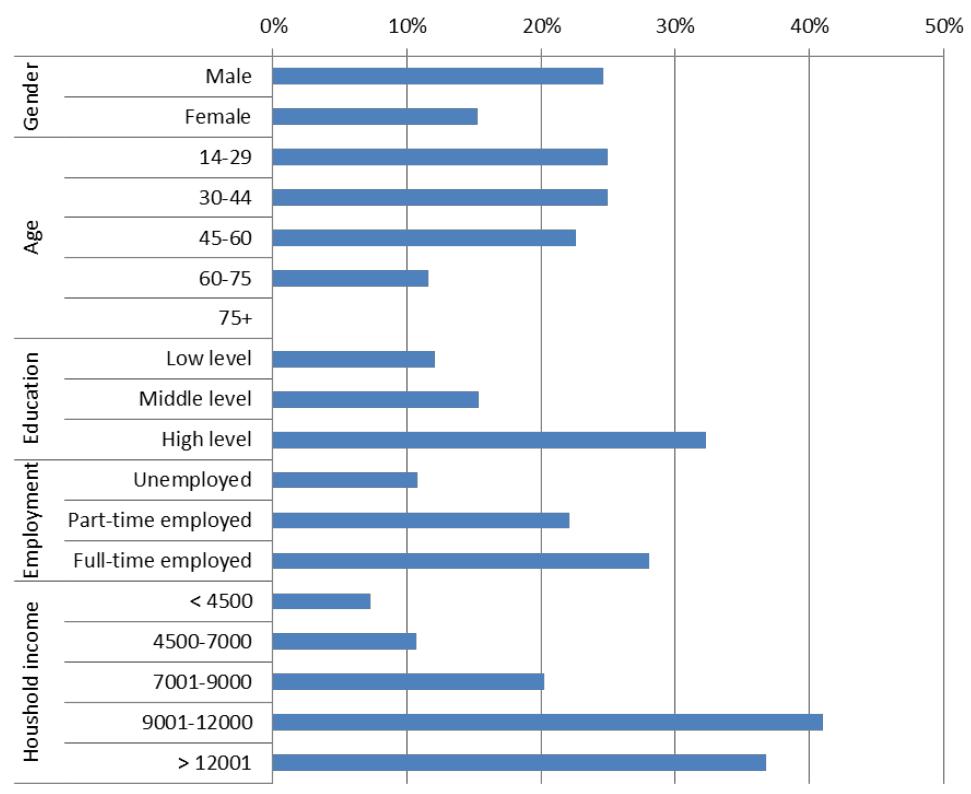

$\mathrm{n}=1104$, Swiss population 14+ (Source: Latzer et al. 2012a: 14) 
Natascha Just, Michael Latzer, Sulkhan Metreveli and Florian Saurwein: Switzerland on the Internet: An overview of diffusion, usage, concerns and democratic implications; In Studies in Communication Sciences, 2013 forthcoming

Figure 2: Use of online social networks

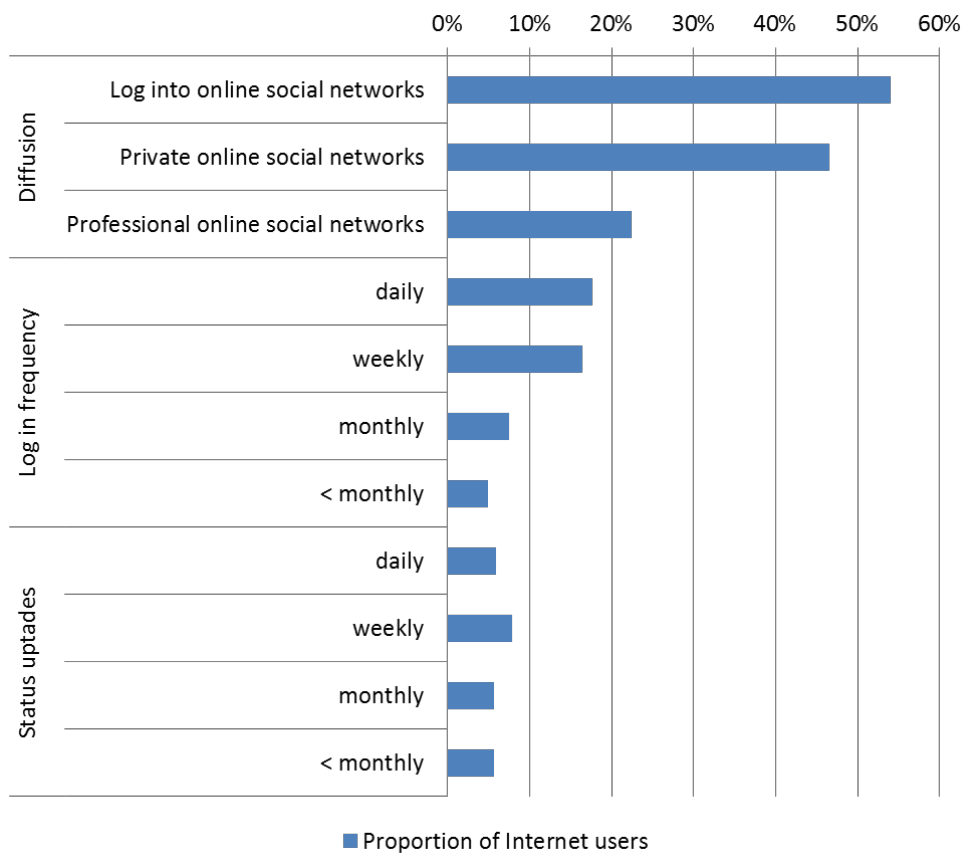

$\mathrm{n}=851$, Swiss Internet user 14+ (Source: Latzer et al. 2012c: 19) 
Natascha Just, Michael Latzer, Sulkhan Metreveli and Florian Saurwein: Switzerland on the Internet: An overview of diffusion, usage, concerns and democratic implications; In Studies in Communication Sciences, 2013 forthcoming

Figure 3: Relevance of sources for information and entertainment

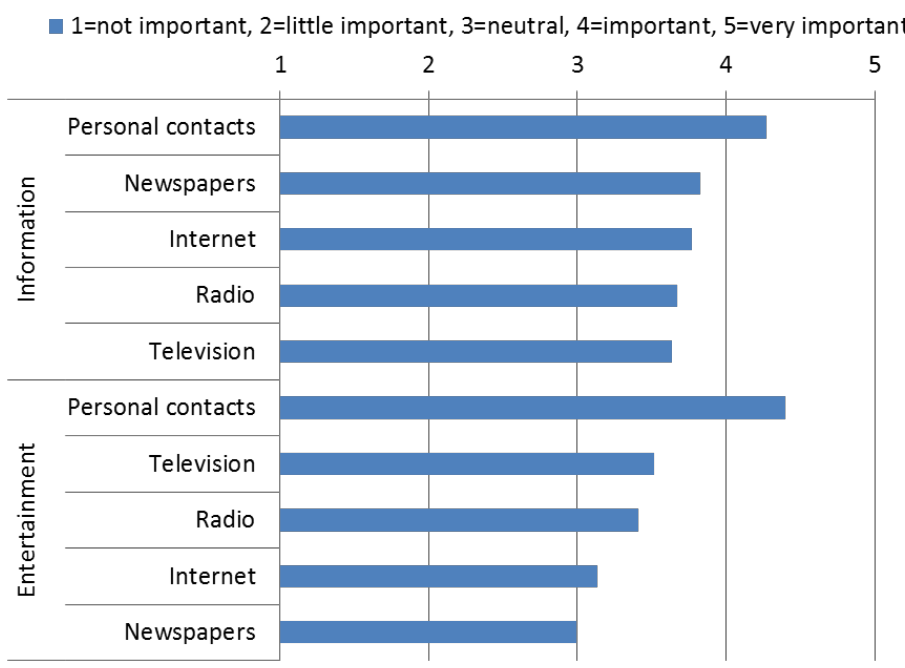

$\mathrm{n}=851$, Swiss Internet user 14+ (Source: Latzer et al. 2012d: 13) 
Natascha Just, Michael Latzer, Sulkhan Metreveli and Florian Saurwein: Switzerland on the Internet: An overview of diffusion, usage, concerns and democratic implications; In Studies in Communication Sciences, 2013 forthcoming

Figure 4: Belief in better political responsiveness

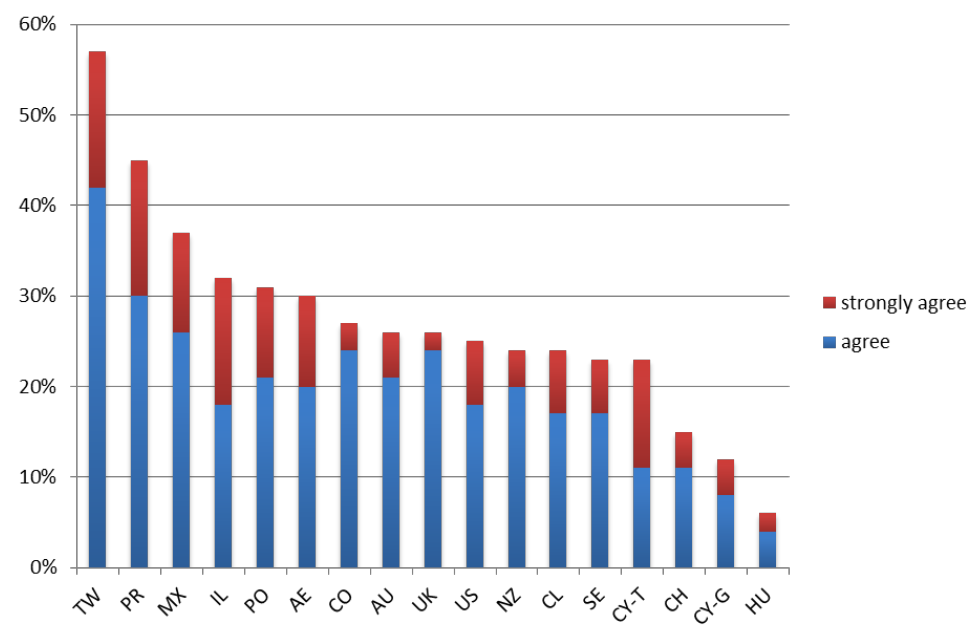

Own figure, based on data of Cole et al. (2012: 129) and Latzer et al. (2012b: 11) 